This article has been published in a revised form in Legal Studies

[https://doi.org/10.1017/lst.2018.53]. This version is free to view and download for private research and study only. Not for re-distribution or re-use. (C) Alysia Blackham.

\title{
An Experimentalist Approach to Equality: A Case Study of Retirement in the UK University Sector
}

\begin{abstract}
Alysia Blackham*
Experimentalism is a theory of regulation in which change is achieved via a process of 'directly deliberative polyarchy' within an experimentalist architecture. This article argues that experimentalism offers a normatively desirable model for legal interventions relating to the ageing workforce, and age equality law in particular, and offers new insights into existing UK scholarship on reflexive law. Drawing on qualitative and quantitative data from UK universities, this article considers the extent to which reforms to retirement ages have promoted a form of experimentalism among UK universities. This article offers concrete suggestions and reforms for how an experimentalist framework could be adopted in this context to enhance regulatory reform.
\end{abstract}

Alysia Blackham, 'An Experimentalist Approach to Equality: A Case Study of Retirement in the UK University Sector' (2019) 39(4) Legal Studies 598-617. 


\section{INTRODUCTION}

In the face of rapid demographic ageing, age discrimination laws are seen as a key means of supporting older workers' workforce participation. ${ }^{1}$ However, age equality laws, of which laws relating to retirement form a key part, experience a number of challenges in their execution and implementation. ${ }^{2}$ Command and control regulation, which seems to typify most discrimination law, cannot effectively address systemic discrimination. ${ }^{3}$ Achieving age equality in practice therefore requires a different regulatory approach.

\footnotetext{
* Associate Professor and Discovery Early Career Research Fellow, Melbourne Law School, The University of Melbourne. This research was funded by a Research Activities Fund Grant from the Society of Legal Scholars, and a Research Grant from the Socio-Legal Studies Association Grants Scheme. The author gratefully acknowledges the comments of Professor Kirsty Gover on an earlier version of this article.
}

${ }^{1}$ See, eg, S Fredman Discrimination Law (Oxford: Oxford University Press, 2nd edn, 2011) p 103.

${ }^{2}$ See, eg, A Blackham Extending Working Life for Older Workers: Age Discrimination Law, Policy and Practice (Oxford: Hart Publishing, 2016); E Dewhurst 'Intergenerational balance, mandatory retirement and age discrimination in Europe: how can the ECJ better support national courts in finding a balance between the generations?' (2013) 50 Common Market Law Review 1333; E Dewhurst 'Are older workers past their sell-by-date? A view from UK age discrimination law' (2015) 78 The Modern Law Review 189; E Dewhurst 'Proportionality assessments of mandatory retirement measures: uncovering guidance for national courts in age discrimination cases' (2016) 45 Industrial Law Journal 60; M Sargeant 'The default retirement age: legitimate aims and disproportionate means' (2010) 39 Industrial Law Journal 244; L Vickers and S Manfredi 'Age equality and retirement: squaring the circle' (2013) 42 Industrial Law Journal 61.

${ }^{3}$ S Sturm 'Second generation employment discrimination: a structural approach' (2001) 101 Columbia Law Review 458, p 475. 
To this end, UK equality law scholarship has focused on the potential for reflexive law to move beyond command and control equality regulation. 4 Experimentalism, which has been less scrutinised in UK scholarship, offers an alternative theoretical frame. ${ }^{5}$ In experimentalism, change is achieved via a process of 'directly deliberative polyarchy' within an experimentalist architecture. ${ }^{6}$ This focuses on both the dispersal of power across many groups - such as government, organisations, and courts - and engagement in thoughtful discussion and dialogue between groups to resolve problems. An experimentalist architecture is an institutional framework of broad policy objectives, information dispersal, a centralised agency for monitoring, and local decision-making, which is ultimately aimed at encouraging actors 'to engage in investigation, information sharing and deliberation about problems. ${ }^{7}$

Experimentalism resembles reflexive law to some extent. ${ }^{8}$ However, it departs from reflexive law in its focus on learning from difference to solve similar problems: ${ }^{9}$

\footnotetext{
4 'Reflexive law' is a theory of law that focuses on the regulation of self-regulation, based on a view of law as an a autopoietic system of communication: see B Hepple 'Enforcing equality law: two steps forward and two steps backwards for reflexive regulation' (2011) 40 Industrial Law Journal 315; C McLaughlin 'Equal pay, litigation and reflexive regulation: the case of the UK local authority sector' (2014) 43 Industrial Law Journal 1; C McCrudden 'Equality legislation and reflexive regulation: a response to the Discrimination Law Review's consultative paper' (2007) 36 Industrial Law Journal 255. ${ }^{5} \mathrm{CF}$ Sabel and J Zeitlin 'Learning from difference: the new architecture of experimentalist governance in the EU' in CF Sabel and J Zeitlin (eds) Experimentalist Governance in the European Union: Towards a New Architecture (Oxford: Oxford University Press, 2012) pp 25-6.

${ }^{6}$ Ibid, p 3 .

${ }^{7}$ CF Sabel and WH Simon 'Minimalism and experimentalism in the administrative state' (2011-2012) 100 Georgetown Law Journal 53, p 81.

${ }^{8}$ Ibid, p 55.

${ }^{9}$ Sabel and Zeitlin, above n 5, p 6.
} 
experimentalism emphasises creating networks of firms that engage in peer review and scrutiny. ${ }^{10}$ Thus, it focuses less on self-regulation, self-referential systems and selfreferencing communication, which are the cornerstones of reflexive law, ${ }^{11}$ and instead considers how firms can engage with each other within a government-influenced regulatory framework. Thus, while both reflexive law and experimentalism focus on private forms of social control, ${ }^{12}$ moving beyond command and control regulation, the experimentalist architecture reflects a more horizontal, non-hierarchical and peer-based model of regulation than reflexive law, and encourages organisations to be more outward-oriented, rather than just focusing on self-scrutiny. Experimentalism focuses on how organisations can engage with and assist each other to achieve equality in practice, through a process of comparison and mutual learning. Thus, it offers new ideas and insights for UK equality law scholarship, beyond those offered by reflexive law.

In this article, then, I argue that experimentalism offers a normatively desirable model for legal interventions relating to demographic ageing. I use experimentalism to critique and normatively model the law relating to retirement ages in the UK. In 2011, the UK national default retirement age ('DRA') was abolished. With the passage of the Employment Equality (Repeal of Retirement Age Provisions) Regulations 2011, SI 2011/1069 (the 2011 Regulations), employers may only adopt an Employer-Justified Retirement Age ('EJRA') where it is shown to be objectively justified as a proportionate means of achieving a legitimate aim.

\footnotetext{
${ }^{10}$ J Cohen and C Sabel 'Directly-deliberative polyarchy' (1997) 3 European Law Journal 313, p 327.

${ }^{11}$ G Teubner "Company interest: the public interest of the enterprise "in itself"' in R Rogowski and T Wilthagen (eds) Reflexive Labour Law: Studies in Industrial Relations and Employment Regulation (Deventer: Kluwer Law and Taxation Publishers, 1994) p 24.

${ }^{12}$ Hepple, above n 4, p 321.
} 
Reforms to retirement ages in the UK potentially integrate an experimentalist model: employers are given space to determine their own organisational priorities within a legislative framework. As part of an experimentalist critique, I empirically evaluate these reforms to the DRA, drawing on qualitative and quantitative empirical evidence from UK universities as a case study of one network of firms. Changes to retirement ages are particularly significant for universities: many academics wish to continue their employment into old age, ${ }^{13}$ and universities therefore have significant incentives to retain retirement ages. ${ }^{14}$ This makes universities a pertinent case for reviewing the EJRA as a form of experimentalism.

I commence with a discussion of experimentalism as a regulatory technique and its normative desirability with respect to age equality (Part 2). I then provide an overview of the law relating to retirement ages in the UK, evaluating the extent to which it reflects experimentalism in practice, and drawing on data from UK universities as one network of organisations (Part 3). While the legal regime is potentially compatible with an experimentalist architecture, it has a number of practical limitations that need to be addressed. Using experimentalism as a normative model of legal regulation, I offer suggestions for legal reform and renewal (Part 4).

\footnotetext{
${ }^{13} \mathrm{~S}$ Manfredi and L Vickers 'Retirement and age discrimination: managing retirement in higher education' (2009) 38 Industrial Law Journal 343, p 357.

${ }^{14}$ See A Blackham 'Managing without default retirement in universities: a comparative picture from Australia' (2015) 35 Legal Studies 502.
} 


\section{USING EXPERIMENTALISM TO ADVANCE AGE}

\section{EQUALITY}

While command and control regulation has traditionally typified most equality law, there is increasing doubt as to whether fixed rules can achieve concrete organisational change and promote equal opportunity. ${ }^{15}$ Command and control regulation is more likely to lead to 'gestures of compliance' than actual organisational change. ${ }^{16}$

As an alternative, then, experimentalism emphasises the role of both central institutions (such as government agencies, legislatures and/or courts), and local institutions (such as employers) in achieving change. Framework goals and measurement criteria are jointly decided by central and lower units, including through experimentation; lower-level units (here, organisations) are then 'given the freedom to advance these ends as they see fit. ${ }^{17}$ Lower-level units report regularly on their performance against the goals, while central units monitor performance, pool information, and promote mutual learning between local units via 'deliberative engagement'. ${ }^{18}$ Framework goals are revised and updated regularly, ${ }^{19}$ drawing on results of earlier reporting processes. Thus, experimentalism combines decentralised control of how goals are to be achieved with centralised coordination of monitoring and

\footnotetext{
${ }^{15}$ CF Sabel Rolling Rule Labor Standards: Why Their Time Has Come, and Why We Should Be Glad of It Proceedings of the International Colloquium on the 80th Anniversary of the ILO Committee of Experts on the Application of Conventions and Recommendations (Geneva: International Labour Organization, 2007) p 264.

${ }^{16}$ Sturm, above n 3, p 461.

${ }^{17}$ Sabel and Zeitlin, above n 5, p 3; see also Sabel and Simon, above n 7, p 79.

${ }^{18}$ Sabel and Simon, above n 7, p 55.

${ }^{19}$ Sabel and Zeitlin, above n 5, p 3; Sabel and Simon, above n 7, p 78.
} 
evaluation. ${ }^{20}$ Experimentalism is best conceived of as an iterative cycle, as shown in Figure 1. The interaction between central and lower units is represented in Figure 2.

Figure 1: Iterative experimentalist process

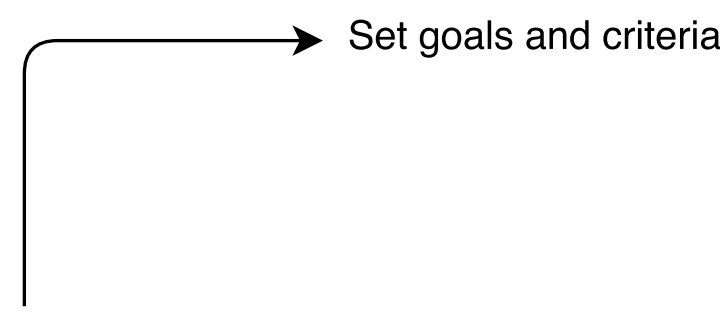

Review goals and criteria


local units to achieve

Participate in peer review

${ }^{20}$ Sabel and Simon, above n 7, p 79. 
Figure 2: Interaction between central and lower units

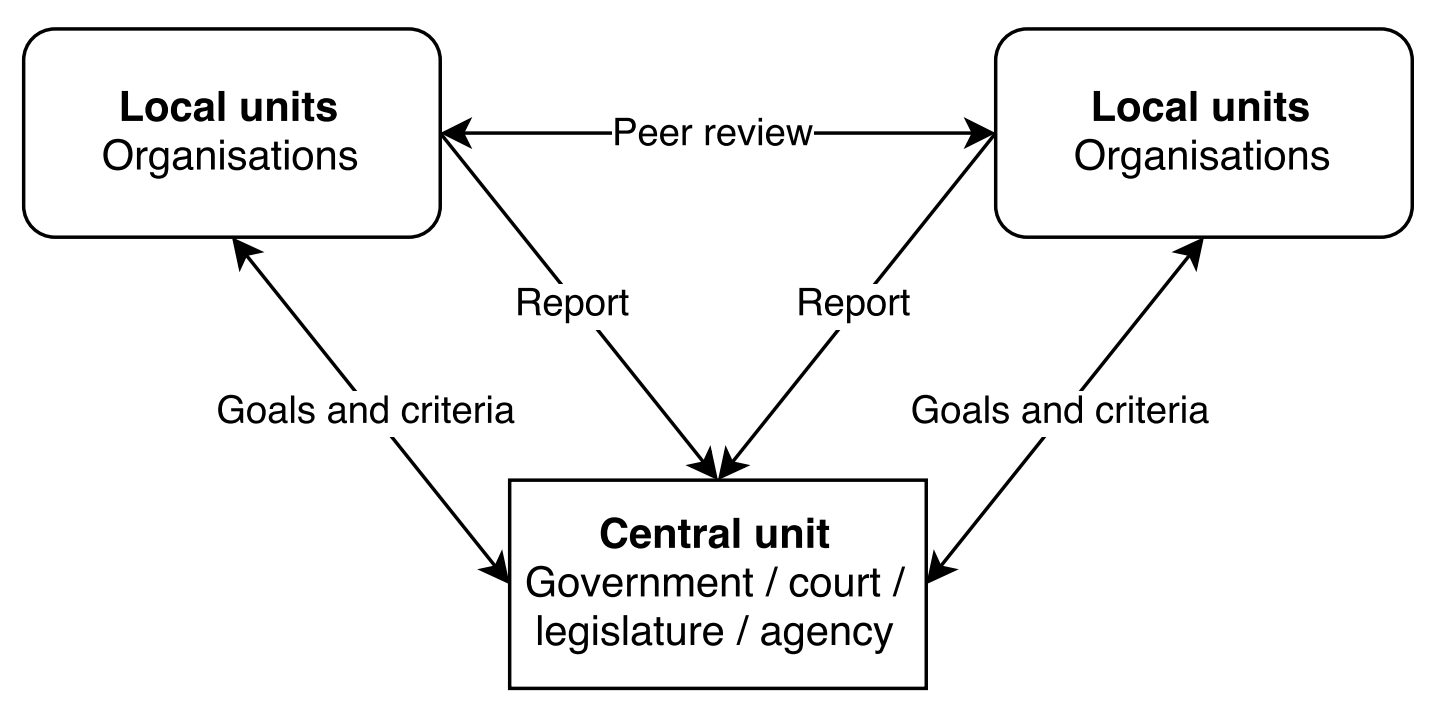

How experimentalism might work in practice is illustrated to some extent by gender equality measures in Australia: the Workplace Gender Equality Act 2012 (Cth) imposes reporting requirements for non-public sector employers and higher education providers with 100 or more employees in relation to gender equality matters. ${ }^{21}$ Employees and employee organisations must be informed when a report is published ${ }^{22}$ and be given an opportunity to comment on the report ${ }^{23}$ to promote workplace consultation on matters of gender equality. ${ }^{24}$ The Workplace Gender Equality Agency

\footnotetext{
${ }^{21}$ Workplace Gender Equality Act 2012 (Cth), ss 3, 13. See further Workplace Gender Equality (Matters in Relation to Gender Equality Indicators) Instrument 2013 (No 1) (Cth). 'Gender equality matters' include equal pay, gender composition of the workforce, flexible work arrangements, and consultation in relation to gender equality.

${ }^{22}$ Workplace Gender Equality Act 2012 (Cth), ss 16, 16A.

${ }^{23}$ Ibid, s 16B.

${ }^{24}$ Ibid, s $2 A(d)$.
} 
is tasked with reviewing compliance with the Act, and collecting and analysing the information provided. ${ }^{25} \mathrm{~A}$ failure to comply with the Act may result in being named by the Agency, ${ }^{26}$ and/or not being eligible to compete for Commonwealth contracts or grants. ${ }^{27}$ Employers of 500 or more employees are also required to comply with minimum standards by putting in place policies or strategies to support one or more of the gender equality indicators. ${ }^{28}$ This offers one example of how experimentalist peer review structures might operate in relation to equality law.

Similarly, the Athena SWAN Charter award scheme in the UK higher education sector provides a strong example of how experimentalism might be implemented in practice. The Athena SWAN scheme is a form of voluntary peer review of gender equality measures. There is considerable qualitative evidence that the scheme has had a positive impact on institutional practices within participating institutions. ${ }^{29}$ Further, the self-assessment process has encouraged institutions to collect equality data and allowed them to identify challenges to gender equality. ${ }^{30}$ Efforts are also being made to promote networking between institutions and the sharing of best practice. ${ }^{31}$ The scheme

${ }^{25}$ Ibid, s 10.

${ }^{26}$ Ibid, s 19D.

${ }^{27}$ See further Department of Families, Housing, Community Services and Indigenous Affairs, Workplace Gender Equality Procurement Principles and User Guide.

${ }^{28}$ Workplace Gender Equality (Minimum Standards) Instrument 2014 (Cth).

${ }^{29}$ See F Munir and others Advancing Women's Careers in Science, Technology, Engineering, Mathematics and Medicine: Evaluating the Effectiveness and Impact of the Athena SWAN Charter (2013).

${ }^{30}$ See Ibid.

${ }^{31}$ Equality Challenge Unit Evaluating the Athena SWAN Charter: ECU Response (2014) p 3. 
is now being linked to research funding, providing an additional positive incentive for participation. $^{32}$

Experimentalism may offer significant benefits to both governments and organisations as they seek to address demographic ageing and achieve age equality. Experimentalist governance may emerge under two conditions: first, strategic uncertainty, where actors must work together to determine what their goals should be and how to achieve them; and, second, a polyarchic distribution of power. Reforms to achieve age equality in employment, including by reforming retirement ages, may satisfy these two conditions. Population ageing is aptly categorised as a 'wicked problem': that is, a policy area which is highly resistant to resolution and has many interdependencies, where the problem is complex, unstable and difficult to define, and where there is no clear solution, thereby requiring a value-based management strategy. ${ }^{33}$ Successfully addressing a wicked problem like ageing requires 'coordinated and interrelated responses', 'trade-offs between conflicting goals', ${ }^{34}$ and difficult normative decisions. ${ }^{35}$

Experimentalism devolves these normative decisions to the local level, facilitating many different responses where no 'right' answer can be imposed centrally. Experimentalism is therefore well suited to areas with significant organisational

32 Equality Challenge Unit About ECU's Athena SWAN Charter (2014), available at http://www.ecu.ac.uk/equality-charter-marks/athena-swan/about-athena-swan/.

${ }^{33}$ HWJ Rittel and MM Webber 'Dilemmas in a general theory of planning' (1973) 4 Policy Sciences 155 , pp 161-7. In this context, 'wicked' is used to describe the nature of the problem itself, and how it might be resolved, rather than the substantive issue at hand.

${ }^{34}$ Australian Public Service Commission Tackling Wicked Problems: A Public Policy Perspective (2007) pp 3-4.

${ }^{35}$ Rittel and Webber, above n 33, p 159. 
diversity, as it facilitates local variation and responsive adaptation to changing conditions: ${ }^{36}$ indeed, local diversity actually enhances experimentalism, as it increases the 'stock of knowledge and experience on which the learning process depends' ${ }^{37}$ In relation to retirement ages, many organisations abandoned compulsory retirement well before the introduction of the 2011 Regulations; others do not yet have the institutional practices in place to manage a workforce without a fixed retirement age. This reflects the diversity in organisational human resource practices across the UK, which is characterised by variations according to organisational size, culture and leadership. Experimentalism, then, allows these variations to be acknowledged and accommodated in the regulatory process, including in the setting of regulatory goals and objectives. This may lead to better substantive outcomes, as well as a more inclusive regulatory process.

Experimentalism also helps to decrease the burden on regulators, by encouraging organisations to self-diagnose and self-correct when they are not meeting goals, standards or benchmarks. ${ }^{38}$ Thus, it reduces the burden of regulatory enforcement on government and central agencies. In addition to potentially being a more effective form of enforcement, as one regulator is not expected to monitor thousands of firms, this also reflects the decline in government spending in an era of austerity. If agencies are, in practice, unable to effectively fulfil a regulatory role due

\footnotetext{
${ }^{36}$ Sabel and Simon, above n 7, p 56.

37 S Deakin Learning or Diversity? Reflections on the Future of International Labour Standards Proceedings of the International Colloquium on the 80th Anniversary of the ILO Committee of Experts on the Application of Conventions and Recommendations (Geneva: International Labour Organization, 2007) p 243.

${ }^{38}$ Sabel and Simon, above n 7, p 88.
} 
to budget cuts, it is pragmatically important to seek alternatives to established forms of government monitoring and enforcement.

While experimentalism potentially offers distinct regulatory advantages, it is also attended by substantial risks. First, giving space to lower-level actors to advance regulatory goals 'as they see fit' ${ }^{39}$ may result in mistakes. Though mistakes might lead to learning opportunities, and open up scope for regulatory improvement, they can also have significant deleterious effects on individual livelihoods and wellbeing. Thus, while theoretically desirable, mistakes may have negative individual consequences in practice.

Second, experimentalism is designed with a specific institutional architecture in mind, involving a strong system of reporting and monitoring, and a central agency that is able and willing to effectively coordinate monitoring and evaluation of local level units. ${ }^{40}$ If this architecture is absent, experimentalism could easily compromise workplace standards, as organisations identify new ways to increase profit margins at the expense of workforce wellbeing. ${ }^{41}$ For Sturm, courts act as the central unit in equality law, specifying general norms and assessing the effectiveness of internal problem solving mechanisms. ${ }^{42}$ Courts become both a 'catalyst and backstop' for organisational reform, incentivising employers to adopt their own problem solving processes, ensuring organisational accountability, and imposing sanctions where

\footnotetext{
${ }^{39}$ Sabel and Zeitlin, above n 5, p 3; see also Sabel and Simon, above n 7, p 79.

${ }^{40}$ Sabel and Simon, above n 7, p 79.

${ }^{41}$ S Bagenstos 'The structural turn and the limits of antidiscrimination law' (2006) 94 California Law Review $1, \mathrm{p} 46$.

${ }^{42}$ Sturm, above n 3, pp 479-482.
} 
problem solving fails. ${ }^{43}$ However, Bagenstos has questioned the ability of courts to evaluate and assess organisational problem solving, noting a tendency of courts to defer to organisational decision-makers. Given judges have limited expertise in organisational management, they may lack both the knowledge and inclination to actively scrutinise workplace processes. ${ }^{44}$ Further, courts in liberal democracies are generally seen as dispute resolution mechanisms, not regulatory bodies per se. Only a handful of disputes ever progress to a full court hearing, meaning it is difficult for courts to effectively assess organisational performance beyond a small proportion of cases. Thus, positing courts as a central unit in an experimentalist architecture is fraught.

This flags the compelling need for some other central unit, such as an equality agency, which can effectively scrutinise organisational practice to facilitate an experimentalist architecture. This central unit should help to compare results across and between individual organisations, and conduct diagnostic reviews to identify and address systemic problems. ${ }^{45}$ This is essential to ensure that experimentalist regimes are protective, rather than a new risk to worker wellbeing. ${ }^{46}$ To achieve this, Sturm emphasises the fundamental role of intermediaries, who sit between the courts and employers, helping to implement structural change in organisations. ${ }^{47}$ Intermediaries might include human resource professionals, lawyers, consultants, unions and employee groups, advocacy groups and insurers. ${ }^{48}$ Intermediaries help to pool

\footnotetext{
${ }^{43}$ Ibid, p 483.

${ }^{44}$ Bagenstos, above n 41, pp 20-1, 25-6.

${ }^{45}$ Sabel, above n 15, p 271.

${ }^{46}$ Ibid.

${ }^{47}$ Sturm, above n 3, pp 522-4.

${ }^{48}$ Ibid, pp 524-37.
} 
information via professional networks and communities of practice, ${ }^{49}$ translate court decisions to effect concrete organisational change, and can act as catalysts for reform. However, Bagenstos has argued that private intermediaries might 'subvert' rather than promote equality, and are at risk of organisational capture. ${ }^{50}$ There is therefore a need for a strong, independent central agency that is capable of filling this intermediary role.

The obvious option, then, is to look to administrative agencies to act as intermediaries. In the UK, this central role could be occupied by the Equality and Human Rights Commission (EHRC). The EHRC has statutory duties to promote understanding and good practice in relation to equality and diversity, promote equality of opportunity, promote awareness and understanding of rights under the Equality Act 2010 (EqA), enforce the EqA, and work towards the elimination of unlawful discrimination and harassment. ${ }^{51}$ It also has a duty to monitor the effectiveness of equality and human rights enactments ${ }^{52}$ and may publish or disseminate ideas or information or give advice or guidance. ${ }^{53}$

While the EHRC has a range of duties and powers which may enable it to act as a central unit or intermediary, significant budget and staffing cuts have severely limited the EHRC's ability to use these powers in practice. ${ }^{54}$ Thus, the EHRC may not have the institutional strength required to effectively enforce age equality law or monitor organisational practice. Further, UK organisations generally do not have

\footnotetext{
${ }^{49}$ Ibid, p 565.

${ }^{50}$ Bagenstos, above n 41, pp 21, 26-34.

${ }^{51}$ Equality Act 2006, s 8.

${ }^{52}$ Ibid, s 11.

${ }^{53}$ Ibid, s 13.

${ }^{54}$ Hepple, above n 4, p 319.
} 
equality reporting obligations to the EHRC, particularly in relation to age equality. There are some areas in which UK employers must publish information: the Equality Act 2010 (Specific Duties) Regulations 2011, SI 2260/2011, for example, requires public bodies to publish information demonstrating their compliance with the Public Sector Equality Duty (PSED), in a manner that is accessible to the public. Further, the Equality Act 2010 (Specific Duties and Public Authorities) Regulations 2017, SI 353/2017 and the Equality Act 2010 (Gender Pay Gap Information) Regulations 2017, SI 172/2017 require most employers with over 250 employees to publish annual gender pay gap reports. Thus, UK employers are required to publish some information, but this does not necessarily mean that the EHRC will have the capacity or inclination to review, monitor or evaluate the published information. ${ }^{55}$ Further, it is unlikely that organisations will review or benchmark against the information published by others, particularly if there is no central agency collating or evaluating that information. In the UK, the absence of a strong, independent central agency that is capable of filling an intermediary role is a serious challenge to the adoption of experimentalism.

Third, and even if an appropriate experimentalist architecture were in place, experimentalism appears silent as to minimum standards, and does not necessarily rule out 'experimentalist solutions of a deregulatory type', ${ }^{56}$ including through a reduction of labour standards. Deakin therefore argues that experimentalism has failed to adequately engage with the risks that downward regulatory competition might pose to

\footnotetext{
${ }^{55}$ See similarly Sturm, above n 3, pp 550-553.

${ }^{56}$ Deakin, above n 37, p 244.
} 
labour standards.$^{57}$ Despite these concerns, Sabel argues that experimentalism can be applied to 'the articulation and vindication of rights', and cites EU age discrimination law as a key example. ${ }^{58}$ Sabel does acknowledge that experimentalism in this area is far less developed than in other fields, and therefore more controversial. ${ }^{59}$ Empirically, however, Sabel does not believe that experimentalism leads to a race to the bottom: rather, firms aspire to rise to the top. ${ }^{60}$ Thus, there is a need to critically monitor and evaluate the use of experimentalism in labour and rights regulation, to determine the impact it might have on labour standards.

Given these concerns, then, an experimentalist model should not be implemented without serious consideration of the risks that might attend a failed experimentalist architecture. At the same time, however, the potential advantages of an experimentalist response to demographic ageing may make it an attractive alternative to command and control regulation. In this context, it is important to critically evaluate how, if at all, experimentalism is modelled in existing regulatory actions in the UK, and how this could be strengthened to avoid regulatory failure.

\footnotetext{
${ }^{57}$ Ibid. A 'floor of rights' approach might help to prevent this race to the bottom, by framing the range of permissible organisational responses: Ibid, p 245.

${ }^{58}$ Sabel, above n 15, p 265. Limited explanation is offered, however, for how this law is experimentalist. ${ }^{59}$ Ibid.

${ }^{60}$ See further Sabel, above n 15.
} 


\section{RETIREMENT AGES IN THE UK AS A FORM OF}

\section{EXPERIMENTALISM}

\section{(a) The law relating to retirement ages}

The law relating to retirement in the UK has undergone fundamental change since 2006. Prior to 2006, employees dismissed on the basis of retirement after reaching an employer's normal retirement age (NRA) or age 65 were unable to claim unfair dismissal or redundancy payments. ${ }^{61}$ With the introduction of age discrimination legislation in the UK, via the Employment Equality (Age) Regulations 2006, SI 2006/1031 (2006 Regulations), a national DRA of 65 was introduced, meaning employers could continue to dismiss staff on the basis of retirement. Employers were also able to retain a NRA lower than 65 if it could be objectively justified. This all changed in 2011: the 2011 Regulations abolished the DRA and removed retirement as a fair reason for dismissal in the Employment Rights Act 1996. Under the 2011 Regulations, employers may still implement an EJRA, so long as the requirement can be objectively justified as a proportionate means of achieving a legitimate aim.

It is unclear what motivated the 2011 change. It may have been driven by the decision of the UK High Court in $R$ (Age UK) $v$ Secretary of State for Business, Innovation \& Skills. ${ }^{62}$ In that case, the Court upheld retirement ages generally as a legitimate social choice made by governments. ${ }^{63}$ However, the Court had concerns regarding the adoption of a DRA of 65 , and whether that particular age was

\footnotetext{
${ }^{61}$ Employment Rights Act 1996, s 109.

${ }^{62}$ [2009] IRLR 1017.

${ }^{63}$ Ibid para 95.
} 
proportionate in light of contemporary conditions. ${ }^{64}$ While the Court declined to grant relief, this was partly due to the government's announcement of a review of the DRA. ${ }^{65}$ Mr. Justice Blake stated: 'I cannot presently see how 65 could remain as a DRA after the review'.66

Prior to even passing the 2006 Regulations, however, the UK government had declared its intention of revisiting the DRA within five years. ${ }^{67}$ Removing the DRA was seen as promoting sustainability of the economy, labour markets and pension systems; promoting adequate living standards in retirement; securing fairness and equality for older workers who did not wish to retire; promoting social inclusion through work; encouraging organisational efficiency, by providing employers with the widest pool of talent; and encouraging intergenerational solidarity, by encouraging individuals to contribute to society through work at all ages. ${ }^{68}$ These aims are illdefined and potentially inconsistent in practice, meaning the removal of the DRA remains theoretically and logically fraught. ${ }^{69}$

\footnotetext{
${ }^{64}$ Ibid para 129.

${ }^{65}$ Ibid para 130.

${ }^{66}$ Ibid para 130.

${ }^{67}$ HM Government Opportunity Age: Meeting the Challenges of Ageing in the 21st Century (2005) p 20.

${ }^{68}$ HM Government The Equality Strategy - Building a Fairer Britain (2010); BIS Flexible, Effective, Fair: Promoting Economic Growth through a Strong and Efficient Labour Market (URN 11/1308, 2011); BIS Phasing out the Default Retirement Age: Government Response to Consultation (URN 11/536, 2011); DWP Fuller Working Lives: A Framework for Action (2014).

${ }^{69}$ See A Blackham 'Addressing the ageing workforce: a critical examination of legal policy objectives and values' (2017) 37 Ageing \& Society 1362.
} 
Unsurprisingly, then, there remains significant legal uncertainty regarding when an EJRA will be 'objectively justified' ${ }^{70}$ The UK Supreme Court decision in Seldon v Clarkson Wright \& Jakes (A partnership) ${ }^{71}$ provides some clarification of the law in this area. In considering the appeal of a solicitor who was compulsorily retired from the partnership at age 65, and drawing on the case law of the CJEU, the UK Supreme Court categorised legitimate aims that might support an EJRA as falling within two broad classes: first, intergenerational fairness; and, second, dignity, ${ }^{72}$ both of which could be applied to the facts in Seldon. While there is now clear guidance as to what aims will be 'legitimate', it is far harder to determine when a retirement age will be a proportionate means of achieving those aims. Indeed, the Seldon decision provided minimal guidance on this point, either at Supreme Court level or in the later Employment Tribunal (ET) and Employment Appeal Tribunal (EAT) decisions. ${ }^{73}$ Any decision on proportionality will be highly fact dependent, meaning it is difficult to craft general rules and guidance. Thus, organisations adopting an EJRA are unlikely to have any certainty as to whether their retirement age is objectively justified, at least until the age is (perhaps inevitably) challenged in the courts.

\section{(b) Retirement ages and an experimentalist framework}

The 2011 Regulations potentially (though, perhaps, unintentionally) engage an experimentalist framework, where employers are given space to determine their

\footnotetext{
${ }^{70}$ See further S Manfredi and L Vickers 'Pensioning off the mandatory retirement age: implications for the higher education sector' (2013) 33 Legal Studies 289, pp 299-308.

${ }^{71}$ [2012] 2 CMLR 50 ('Seldon').

${ }^{72}$ ibid [56]-[57].

${ }^{73}$ Seldon v Clarkson Wright \& Jakes [2013] UKET 1100275/2007 (14 May 2013); Seldon v Clarkson Wright \& Jakes [2014] UKEAT/0434/13/RN (13 May 2014).
} 
organisational priorities and needs in relation to retirement by adopting an EJRA where it can be objectively justified. This gives scope to employers to 'experiment' with retirement ages and other forms of workforce management within the legislative framework. This stands in stark contrast to some other forms of labour regulation, such as the use of minimum standards of employment.

Of course, this is not to imply that government officials had experimentalism in mind when drafting the 2011 Regulations: $:{ }^{74}$ as Hepple has noted in relation to reflexive law, 'grand theories ... may have little impact on the actual development of legal enforcement' and legal policy; politicians may fail to grasp fundamental aspects of regulatory theory, or can choose to 'ignore them' ${ }^{75}$ Thus, while reforms to retirement ages raise the prospect of experimentalism, they may well do so unwittingly or unintentionally.

In the sections that follow, I use empirical evidence from UK universities, as a case study of one network of firms, to consider how organisations are responding to the 2011 Regulations. This provides a grounded means of evaluating (potentially) experimentalist architectures, and considering how organisations are responding to these reforms in their internal processes. The case study organisations included three universities that had adopted an EJRA, and four that were operating without a retirement age. ${ }^{76}$ The case studies included semi-structured interviews with Directors

\footnotetext{
${ }^{74} c f$ the PSED, which was intended to operate as a form of reflexive law: S Manfredi, L Vickers and K Clayton-Hathway 'The Public Sector Equality Duty: enforcing equality rights through second-generation regulation' (2018) 47 Industrial Law Journal 365, p 373.

${ }^{75}$ Hepple, above n 4, p 334.

${ }^{76}$ In this paper, a classification scheme is used to enable the broad identification of universities while still maintaining source and case study anonymity. Universities have been allocated a number, and each
} 
or senior members of the universities' Human Resource, Legal Services and/or Equality Units, and a documentary review of university policies and other documents. ${ }^{77}$ Interviews were also conducted with institutional representatives of the University and College Union where possible. Nine interviews were conducted in total across the study. This qualitative data was compared with quantitative data from Freedom of Information requests sent to all UK universities and all Oxford and Cambridge colleges (220 institutions in total). After multiple follow-ups, responses were ultimately received from 169 institutions over the course of 2015.

Using this empirical data, the operation of UK retirement rules as a form of experimentalism can be critiqued across the four phases of the iterative experimentalist architecture: setting goals and measures; discretion to pursue goals and measures; peer review and scrutiny; and review and revision of goals.

\section{(i) SETTING GOALS AND MEASURES}

Rather than removing retirement ages entirely (which would be a form of command and control regulation), the law now allows an EJRA to be adopted where it is a proportionate means of achieving a legitimate aim. This, at least superficially, moves beyond the use of fixed rules in relation to retirement.

Beyond this rule, however, it is difficult to identify framework goals or measurement criteria in relation to retirement ages in the UK, such as would be required

\footnotetext{
interviewee from that university identified with a different letter. So the second respondent from the fifth university is identified with U5b. Where identifying the university would jeopardise source anonymity (e.g. for universities with an EJRA, which are few in number and publicly known), no source has been cited.

${ }^{77}$ See MQ Patton Qualitative Evaluation and Research Methods (Newbury Park: Sage, 2nd edn, 1990) p 467.
} 
for an experimentalist architecture. The 2011 Regulations establish a binary system in relation to retirement: employers either have an EJRA; or they do not. For those that adopt an EJRA, the 'criteria' that are used to assess the validity of that policy - whether the retirement age is a proportionate means of achieving a legitimate aim - are not framed in relation to broader goals or objectives, though broader goals are imported through the reference to 'legitimate aims'. While the standard for adopting an EJRA was originally set by the legislature in the 2011 Regulations and EqA (implementing the provisions of the EU Framework Directive ${ }^{78}$ ), the justification of retirement ages is scrutinised by courts and tribunals as central units, who help to elaborate the standard and criteria employers must meet if keeping a retirement age. ${ }^{79}$ The objective justification process creates incentives for employers to devise their own regimes and plans in relation to retirement, that are tailored to their particular circumstances. ${ }^{80}$

However, while courts play a fundamental role in facilitating and scrutinising experimentalism, early ET decisions on EJRAs provide limited clarity on the criteria that will be used to assess retirement ages. Relatedly, there is also limited guidance from ETs and courts in relation to the 'criteria' or goals created by the 2011 Regulations, which likely prevents organisations from confidently experimenting with retirement ages. ${ }^{81}$ There is limited consistency between the handful of ET decisions on

\footnotetext{
${ }^{78}$ Council Directive 2000/78/EC of 27 November 2000 establishing a general framework for equal treatment in employment and occupation [2000] OJ L 303/16.

${ }^{79}$ BL Garrett and JS Liebman 'Experimentalist equal protection' (2004) 22 Yale Law \& Policy Review $261, \mathrm{p} 292$.

${ }^{80} \mathrm{Ibid}, \mathrm{p} 315$.

${ }^{81}$ Arguably, however, in an experimentalist structure this guidance should come from the legislature or executive, or a central agency (like the EHRC), not the courts.
} 
EJRAs, with substantial variation regarding the level of evidence that will be required to prove proportionality. ${ }^{82}$ ETs are often unwilling to subject employer retirement ages to a high standard of scrutiny, and sometimes give significant latitude to employers in adopting EJRAs, though the cases diverge wildly on this point. ${ }^{83}$ This partly reflects the fact-dependent nature of the proportionality test. However, ETs may also lack the expertise and inclination to actively scrutinise workplace processes and problem solving. ${ }^{84}$ This is arguably exacerbated by the fact that there is limited guidance more generally as to the object and purpose of the 2011 Regulations.

Conversely, for employers who choose to abandon retirement ages, there is no external goal, measurement criteria or scrutiny. Thus, the 2011 Regulations have created a two-tier system for employers: those who choose to adopt retirement ages will be subject to (possibly significant) scrutiny by courts if the retirement age is challenged; those who do not, will be exposed to minimal (if any) scrutiny. This situation may be compared to that in relation to other equality provisions, where criteria apply to all employers. ${ }^{85}$ Given employers can avoid liability and court scrutiny by simply not

\footnotetext{
${ }^{82}$ See Blackham, Extending Working Life for Older Workers, above n 2, 3.

${ }^{83}$ For example, the ETs in Seldon (n 73), Lindsay v Department for Employment and Learning [2014] EqLR 180 and White v Ministry of Justice ET 2201298/2013 (20 November 2014), conducted a far less rigorous inspection of the retirement ages in question than that in Hampton v Lord Chancellor [2008] IRLR 258, Engel v Transport and Environment Committee of London Councils [2013] UKET 2200472/2012 (26 April 2013), Martin v Professional Match Game Officials Ltd [2010] UKET 2802438/2009 (13 April 2010) or Willey v England and Wales Cricket Board Ltd [2015] UKET 2201406/2014 (10 March 2015).

${ }^{84}$ Bagenstos, above n 41, pp 20-1, 25-6.

${ }^{85}$ For example, Sturm considers the case of an affirmative defence to claims of sexual harassment, which could apply to any employer in appropriate circumstances.
} 
adopting an EJRA, there are few incentives for employers to engage in the process of justification established by the 2011 Regulations. Indeed, it is likely that employers will only adopt an EJRA if the alternative - abandoning fixed retirement ages - is so unpalatable that the risks of legal scrutiny are outweighed by organisational pressures. This implies that few, if any, organisations will engage in the process of justification and experimentation made possible by the 2011 Regulations - indeed, there are substantial negative incentives against engaging in this process. ${ }^{86}$

Even if there were clear goals and measures in the 2011 Regulations, they were not set collaboratively by both central and lower units, as experimentalism requires. Government consultation on the 2011 Regulations ${ }^{87}$ happened very quickly and did not fully engage with individual employers. Further, it is clear that legal reform was driven by government, rather than being managed collaboratively by government and employers. In the case studies of universities that adopted an EJRA, it was noted that the implementation of an EJRA 'felt quite rushed': the 2011 Regulations were introduced with limited warning, and new processes had to be adopted internally at short notice. As another institution noted, the adoption of an EJRA is a 'long process', entailing consultation, dialogue and focus groups. For one institution, a longer lead time on the legislative change would have allowed more extensive consultation within the

\footnotetext{
${ }^{86}$ This may be compared with other areas of law, where participation can be induced by potential civil liability: Garrett and Liebman, above n 79, p 293. Here, participation is deterred by potential civil liability.

${ }^{87}$ BIS Phasing out the Default Retirement Age: Government Response to Consultation. Impact Assessment (BIS/11/634, 2011); BIS Phasing out the Default Retirement Age: Consultation Document (URN 10/1047, 2010); BIS, Phasing out the Default Retirement Age: Government Response to Consultation, above $\mathrm{n} 68$.
} 
university, and would have given staff more time to become comfortable with the new processes. Another university similarly wondered whether there would have been fewer challenges to retirement ages if the law had been changed more slowly. Thus, a longer and more collaborative lead-time on the changes to the DRA might have allowed the institutions to adopt a different approach, either by not adopting a retirement age or by undertaking a more comprehensive programme of consultation to cultivate community buy-in to their EJRA. ${ }^{88}$ The development of goals and measures by both central and lower units might have facilitated a more thoughtful and responsive organisational reaction to legal change, potentially facilitating a more experimentalist response at the organisational level. Experimentalism therefore draws attention to the need for effective engagement of lower-level units in the process of legal change, encouraging a less top-down approach to reform.

\section{(ii) DISCRETION TO PURSUE GOALS OR MEASURES}

It is questionable, then, whether this legal structure actually provides space for employer discretion or experimentation in relation to retirement ages. Certainly, following the 2011 Regulations, employers may choose to adopt an EJRA, and have discretion in choosing the age of retirement and the process to be adopted when employees are retired, so long as this is regarded as 'proportionate' if challenged. This facilitates and encourages diversity in organisational practices and experimentation

\footnotetext{
${ }^{88}$ Though some institutions managed to undertake fairly substantial consultation prior to adopting an EJRA: see C Barnard and S Deakin 'Age discrimination and labour law in the UK: managing ageing' in A Numhauser-Henning and M Rönnmar (eds) Age Discrimination and Labour Law: Comparative and Conceptual Perspectives in the EU and Beyond (Alphen aan den Rijn: Kluwer Law International, 2015) pp 314-316.
} 
among employers in relation to retirement, at least in theory. It also allows employers to adopt a retirement policy that suits their particular needs.

However, beyond this theoretical possibility, in practice it appears that the EJRA justification process has significantly constrained employer discretion. Many employers have chosen to abandon fixed retirement ages in the UK. ${ }^{89}$ In early surveys of employers, somewhere between $2.9 \%{ }^{90}$ and $19 \%{ }^{91}$ of respondents reportedly chose to adopt an EJRA. This low level of uptake is understandable, given the level of court scrutiny that potentially attends the adoption of an EJRA, and the lack of clarity regarding what is 'proportionate'. This means the standards set by the 2011 Regulations apply to only a very small proportion of the UK workforce - that is, those that have chosen to adopt an EJRA. This also implies that retirement age reform is not leading to experimentation in practice - rather, the default is to remove retirement ages.

This is consistent with the results of the FOI survey: of the responding universities, only four had adopted an EJRA: Oxford (and some, but not all, of its colleges) (with an EJRA of 67 years), Cambridge (and some, but not all, of its colleges) (67 years), St Andrews (the state pension age) and Westminster (75 years). The vast majority had removed their retirement age in 2011. Thus, there appears to be limited experimentation among UK universities in relation to retirement ages.

${ }^{89}$ DWF De-Regulation of Retirement - One Year On (2012), available at http://web-archiveuk.com/uk/d/dwf.co.uk/2012-07-

19_157064_88/DWF_gt_De_regulation_of_Retirement_One_Year_On/. See also Eversheds Eversheds UK HR E-Briefing: How Are Employers Managing without the Default Retirement Age? (2013); R Thomas and others Recovery in Sight? The State of HR (2013).

${ }^{90}$ Eversheds, above n 89, p 2.

91 Thomas and others, above n 89, p 9. 
Among the institutions that have adopted an EJRA, there is some variation in how the retirement age is framed and implemented, reflecting a degree of discretion in the implementation of retirement rules. More particularly, the universities differ in the retirement age adopted; whether the age applies to both academic and support staff (e.g. Oxford $^{92}$ ), or just academic staff (e.g. Cambridge); provision for considering requests to work beyond the EJRA; and when those requests to continue work will be approved. However, the universities reflect similar concerns in their reasons for adopting an EJRA, and the aims supporting their retirement ages. ${ }^{93}$ Thus, there is some experimentation and discretion in practice, at least among the four institutions with an EJRA.

There is also evidence of experimentation within institutions with an EJRA, particularly in relation to requests to work beyond the retirement age. One case study institution noted that they had received many requests to continue working, and more than were initially expected. The majority of these requests included a persuasive case for continuing to work, and the staff were allowed to remain at the university. The right to request process was encouraging staff to think about how the effects of later retirement might be mitigated, facilitating discussion between employees and managers about future plans. Thus, while 'stark numbers' indicated that few staff were being retired under the EJRA, a number of deals were being struck that facilitated a 'win all round' (for example, by employing staff over retirement age in a fixed term research

\footnotetext{
${ }^{92}$ Note, however, that Oxford revised its EJRA policy from 1 October 2017 to apply to staff in grade 8 and above only: see Personnel Services, Employer Justified Retirement Age (2017), available at http://www.admin.ox.ac.uk/personnel/end/retirement/acrelretire8+/ejra/.

${ }^{93}$ This may reflect a process of peer-review: see below. Alternatively, it may show the impact of court decisions on university problem-solving.
} 
post, financed through grant money). This implies a level of experimentation at the local faculty level, as individual units and groups were negotiating to ensure optimal outcomes between employers and employees, within the institutional framework. At the same time, there was a level of 'discomfort' in the central university regarding the number of applications to continue working that were being accepted, as this might undermine the justification of the retirement age. Thus, external criteria imposed by courts might undermine experimentation within an institution, and prevent tailored organisational responses to demographic ageing.

While potentially facilitating tailored and adapted solutions to demographic ageing, delegating requests to continue to be managed at the local department or faculty level also carries risks. In that same case study, the institution's union representative expressed concerns that managing requests to continue at the individual level could lead to injustice and unfairness, raising complex questions regarding how the policy was implemented locally, and whether the same criteria would be applied in different departments. ${ }^{94}$ Further, the process of applying to continue may require older academics to over-perform when compared with their younger colleagues, particularly where they are required to find research grants to support their continued employment. ${ }^{95}$ Thus, experimentation does not necessarily lead to normatively desirable outcomes locally. ${ }^{96}$ In response to these concerns, the university was focusing on building the capacity of those who were assessing applications, and refining the criteria for evaluating requests, to ensure applications were only approved in

\footnotetext{
${ }^{94}$ See similarly M Emery Academia, Oxford University and Retirement (2014), available at http://www.withyking.co.uk/blog/academia-retirement-policy/.

${ }^{95}$ See similarly Ibid.

${ }^{96}$ Or, perhaps, even more broadly if this cultivates a race to the bottom.
} 
exceptional cases. This will likely prevent or inhibit lower-level experimentation and tailoring. Thus, there is an obvious tension between experimentation and equality of treatment.

For other universities without an EJRA, there is far less evidence of experimentation and discretion. Rather than engaging in experimentation, it appears that the 2011 Regulations have effectively created fixed rules in relation to retirement, with scope for only the most courageous universities to tailor provisions to their individual needs. This was even recognised in the case study organisations with an EJRA: in one university, the representative expressed concern that, by adopting an EJRA, it might be 'swimming against the tide' of legislation. This implies that there is no shared goal or purpose between central and local actors. Similarly, another EJRA institution felt that their EJRA had a relatively 'finite life', as it was out of sync with developments in pension law and the raising of the state pension age. The EJRA was just a 'sticking plaster' to allow the university to manage the transition to a more performance oriented culture.

Thus, even the EJRA universities did not see the 2011 Regulations as being something that encouraged experimentation - rather, they recognised a significant but manageable risk of legal action associated with being an experimenter. While the universities accepted this risk, this was perhaps because the costs of not experimenting were far higher than the risks of legal action. Where retirement ages were adopted, the reasons cited for the policy included: very low turnover, which may limit progression for other staff; increasing the diversity of staff (consistent with the institution's PSED under the EqA); refreshing the workforce; and facilitating succession planning (particularly given the time required to recruit a professor). These were seen as major challenges for the institutions, which made the risk of legal challenge comparatively 
acceptable. One institution noted that, while adopting an EJRA had presented a number of practical issues, the respondent was sure the university would have had 'more issues if we'd gone down the performance management line'.

Among the non-EJRA institutions responding to the FOI survey, many universities had no documents on record explaining why an EJRA was not adopted, implying that there was limited deliberative dialogue in the process. At least five universities noted that they had never formally considered having an EJRA; five others felt that they could not justify a retirement age; and five felt that a retirement age was not necessary or in the best interests of the organisation. Most institutions without an EJRA had simply removed their retirement policy following the 2011 Regulations, and did not consult on the change: at most, a management committee made the decision. For the majority of responding institutions, retirement is now dealt with like any other resignation. Only one university (Kingston) noted that their approach was consistent with that across the higher education sector, flagging a degree of inter-organisational benchmarking in at least one institution. For the most part, however, the 2011 Regulations did not appear to have prompted reflection or consideration about retirement ages or demographic ageing in non-EJRA universities (or at least none that was recorded).

Thus, rather than a system of experimentation, the 2011 Regulations appear to have created a rule-based system. This is consistent with the findings in relation to goals and measures above: where goals are unclear (or non-existent), it is difficult to give organisations discretion; and where EJRAs are seen as legally risky, with limited guidance as to what is justified, this is likely to deter experimentation. This, then, is not a presumptive rule typical of an experimentalist architecture (e.g. that organisations will operate without a retirement age). Presumptive rules need not be followed if doing 
so would undermine the underlying purposes of the rule, so long as the organisation can justify and explain its decision. ${ }^{97}$ Instead, in this context, the rule appears to be closer to a fixed rule for most employers.

A move to a rule-based system in this way is likely to deter employers from engaging in problem solving behaviour to promote age equality, including via the collection and analysis of data. Rule-based regulation often creates a fear of legal action and a focus on thwarting legal challenges, rather than a focus on addressing inequality through data collection and analysis. ${ }^{98}$ This can be seen in the FOI data: universities without a retirement age were asked to provide the average age of retirement for their academic and support staff. Nineteen institutions did not collect this data. Similarly, institutions were asked to provide statistics relating to performance management of older workers - again, 23 institutions had no central electronic record of this data. Thus, institutions that are not engaging in the EJRA process have limited incentives and reasons to address the bigger challenges of population ageing, or to collect data that might identify issues or flag institutional challenges. This can also be seen in the results of the organisational case studies: few institutions without an EJRA had any proactive measures in place to address the demographic ageing of their workforce, and age equality was not seen as a priority for most institutions.

At the same time, experimenting institutions with an EJRA were not always more active or prepared in relation to age equality, implying that experimentation does not necessarily encourage a more proactive approach to equality generally. For example, while asserting the link between adopting an EJRA and improving staff diversity, one institution noted that it had limited reliable data regarding the proportion

\footnotetext{
${ }^{97}$ Sabel and Simon, above n 7, p 80.

${ }^{98}$ Sturm, above n 3, p 476.
} 
of Black and Minority Ethnic (BME) or disabled staff in the university. However, younger staff were thought to be more ethically diverse, and more women were being employed in senior roles over time. Thus, it was thought that the EJRA was an effective means of promoting diversity, as the differences between the diversity of older and younger staff members were 'really stark' ${ }^{99}$ Rather than being driven by data, the diversity argument was largely grounded in anecdotal evidence, and was actually rejected by a different institution, which felt that it was inappropriate for gender equality to 'trump older people and their rights'.

\section{(iii)REVIEW AND SCRUTINY}

If employers choose to adopt an EJRA, they must also participate in a process of justification and explanation. In the case study institutions, this was undertaken through internal consultation, policies and process documents; it would only be continued in the court and tribunal system if the EJRA was challenged. If employees challenge an EJRA via a claim to an ET, then employers have a duty to explain why the EJRA is a proportionate means of achieving a legitimate aim. Courts act as a backstop, and ensure the accountability of employers. In sum, then, the process of adopting and justifying a retirement age could facilitate deliberative dialogue and engagement between employers, employees (and possibly unions) and the courts.

While this appears attractive in theory, review and scrutiny of retirement practices in the UK is limited in practice. First, there is no requirement for local actors to share information about their EJRA with other local actors, meaning there are few

\footnotetext{
${ }^{99}$ In contrast, union representatives felt that retirement ages were not an effective means of promoting equality, as more diverse candidates were not applying for vacant positions, and did not 'understand the rules' for getting short-listed for positions when they did apply. Thus, retirement ages were ineffective at achieving diversity without broader change.
} 
information flows between local units. Second, there is no central agency collecting information about the adoption of EJRAs, and no obligation on employers to report on their retirement practices. Third, as discussed above, courts are limited in the degree to which they can effectively scrutinise organisational practices. Thus, this framework of review and scrutiny differs substantially from that envisaged by an experimentalist model.

These limitations are demonstrated by the findings of the case study. Despite the risk of legal challenge inherent in adopting an EJRA, few legal claims had been brought in the universities studied. The EJRA at Oxford was the only retirement age to have been challenged, including via a number of internal appeals ${ }^{100}$ and a legal claim in the ET. ${ }^{101}$ The process of internal review at Oxford provides some accountability for and scrutiny of organisational processes. However, the review has generally been conducted in secret, and there are few public records of the process or decision. Thus, there is limited public scrutiny of the EJRA in this context. With reductions in legal aid funding, it is also becoming more difficult for employees to challenge employer practices using legal mechanisms. This means that the public justification requirement for EJRAs, which is only activated when an individual complaint is made to an ET, is unlikely to come into play in most cases. This is of particular concern as the quality of justification that is occurring at the organisational level is often questionable: in a survey of employers, of the $19 \%$ of respondents that had retained a retirement age for their workforce, the majority failed to provide a justification for their retirement age

\footnotetext{
${ }^{100}$ In the Oxford University Court of Appeal: In the Appeal of Professor Denis Galligan (1st September 2014), cited in DJ Galligan 'Goodbye to the EJRA' [2015] Oxford Magazine 4.

101 'Oxford professor "told to retire at 67 to allow diversity"' The Telegraph (20 August 2018). Though, at the time of writing, a decision had not yet been handed down.
} 
when asked. ${ }^{102}$ Thus, reliance on individual enforcement and court scrutiny of EJRA experimentation is unlikely to promote effective accountability and scrutiny.

That said, there may be an emerging form of peer review and benchmarking in relation to retirement ages, as is envisaged by experimentalism. In the case law on EJRAs, one factor which will weigh heavily in the courts' decision-making on proportionality is whether a less discriminatory alternative to a retirement age is shown to be practicable, either in the same organisation, ${ }^{103}$ a similar organisation, ${ }^{104}$ or even hypothetically. ${ }^{105}$ If an alternative is practicable, it is highly unlikely that the retirement age will be proportionate. Conversely, if available alternatives would be ineffectual ${ }^{106}$ or create 'chaos', ${ }^{107}$ this will tend towards a finding of proportionality. ETs making reference to the practices in other organisations are likely to encourage organisations to review the policies and practices of their peers, and may encourage more structured inter-organisational benchmarking in relation to retirement ages. The EJRA justification process may now mean that unilateral solutions to retirement are no longer acceptable: ${ }^{108}$ if other, similar employers can manage their workforce without mandatory retirement, this might undermine an EJRA's justification.

Thus, age equality law in the UK could increasingly be moving to a polyarchic distribution of power, flagging the potential for an experimentalist architecture to effect

\footnotetext{
102 Thomas and others, above n 89, p 9.

${ }^{103}$ Hampton (n 83).

${ }^{104} \operatorname{Martin}(\mathrm{n} 83)$.

105 See Engel (n 83) [47].

${ }^{106}$ Lindsay (n 83).

107 Willey (n 83).

${ }^{108} \mathrm{CF}$ Sabel and J Zeitlin 'Experimentalism in the EU: common ground and persistent differences' (2012) 6 Regulation \& Governance 410, pp 413-14; Sabel and Zeitlin, above n 5, p 15.
} 
change. Indeed, the marked similarities between the legitimate aims in the retirement policies of the EJRA case study institutions flag the very real possibility of interorganisational benchmarking. This is facilitated by the fact that each institution (bar the University of Westminster) posts their retirement policy publicly online. That said, each case study institution was keen to explore what others were doing in relation to retirement, implying that there is no active or formalised discussion between institutions, though administrators are watching developments in other universities closely. Despite the obvious desire among respondents for some pooling of information between institutions, the process of adopting an EJRA more closely resembles a costbenefit analysis, where the risks of legal challenge are weighed against the risks of operating without retirement ages, rather than an experimentalist process of peer benchmarking and consultation.

This lack of peer review and benchmarking is consistent with the findings of the organisational case studies for institutions without an EJRA. Respondents were very conscious of what was occurring elsewhere, and often framed their policies in juxtaposition to what was happening in EJRA institutions. One institution was advised that its corporate structure was sufficiently different to the collegial 'community of scholars' at Oxford and Cambridge that justifying a retirement age would be problematic (U4). The process at Oxford and Cambridge therefore appears to have set a benchmark that other institutions either meet (and adopt an EJRA) or fail to meet (and remove retirement ages entirely). This is far from the sort of organisational learning and peer review envisaged by experimentalism. ${ }^{109}$

\footnotetext{
109 Though, it does flag that legal advisors could fulfill an intermediary role in this situation.
} 
Inter-organisational benchmarking is inhibited by the limited obligations of UK universities to report on their age equality performance and retirement policies. As public bodies, UK universities must generally comply with the PSED and associated specific duties, which require public sector employers to publish information to demonstrate their compliance with the general equality duty. ${ }^{110}$ The PSED has created some information flows between public organisations, as policies and procedures are generally posted on organisational websites; and FOI requests allow additional information to be requested and obtained. However, this approach is only effective where institutions actually collect relevant data.

Reform to retirement rules does not appear to have improved data collection in most institutions, which makes inter-organisational benchmarking fundamentally problematic: there is nothing to compare. One non-EJRA institution had not seen much evidence of workforce planning or the use of workforce data (U4), and another was 'not as attentive' as they would like to be to planning and the use of workforce statistics (U5a). Another had no information about the age profile of its workforce (U6). Even where data was collected, it was up to individual academic managers to interpret the information provided by central university bodies, and this occurred only rarely (U5a). Even if information had been available, one institution questioned what they could actually do with it - what is the standard or ideal workforce composition based on age? (U6) This relates to the challenge of developing goals and measures in this area. Bucking the general trend, one non-EJRA institution noted that, as a result of the removal of the DRA, it was focusing more seriously on the collection of workforce information, including in relation to age and other protected characteristics (U3). This

\footnotetext{
${ }^{110}$ Equality Act 2010 (Specific Duties) Regulations 2011, SI 2011/2260, reg 2.
} 
information was provided to deans and senior management to flag potential issues in individual departments. Further, a commitment had been made to develop equality action plans in individual faculties, with annual reporting on progress to the University council (U3). The university had also appointed Age Champions to consider and advance these issues at the institutional level (U3). This stands in marked contrast to what appears to be happening in other institutions. As noted in one non-EJRA institution, 'all of our equality eggs [have been put] into the gender basket', meaning age has 'almost become a silent category' (U6). Age is being largely ignored as a protected characteristic, and there is minimal proactive action being taken to promote age equality (U6).

Overall, then, proactive responses to ageing and improved information flows may be emerging at some institutions, though this is far from the norm. This makes it unsurprising that there is a noticeable lack of a 'benchmarking logic' between employers in the UK, and an absence of discussion among employers generally about best practice in relation to age equality. ${ }^{111}$ Thus, it is questionable whether there is any effective peer review or inter-organisational benchmarking in relation to retirement ages. This is exacerbated by the lack of a central body tasked with exposing difference between employers ${ }^{112}$ to encourage inter-organisational comparison. ${ }^{113}$ The EHRC could perform this centralised role with additional resourcing and more targeted powers and responsibilities. Current trends towards reducing the EHRC's role and resourcing run directly counter to an experimentalist architecture. Private intermediaries are also unlikely to play a large role in the UK in relation to retirement. First, the limited union

\footnotetext{
${ }^{111}$ Cohen and Sabel, above n 10, p 326.

${ }^{112}$ Sabel and Zeitlin, above n 5, p 4.

${ }^{113}$ Sabel and Simon, above n 7, p 79.
} 
presence and membership in UK workplaces has reduced the capacity for unions to exert influence on employers in this area. ${ }^{114}$ In 2013 , only $25.6 \%$ of UK employees were members of a trade union, down $6.8 \%$ since $1995 .{ }^{115}$ Second, the comparatively weak litigation culture in the UK (at least when compared with the US) means active scrutiny of employers by individual lawyers is unlikely to occur. Third, while the Chartered Institute of Personnel and Development (CIPD), a professional association for HR workers, promotes information pooling and networking by its members, including in the area of ageing, ${ }^{116}$ many UK employers (particularly SMEs) will not have a specialist HR function. Given SMEs represented $99.9 \%$ of all private sector businesses in the UK in 2015, and $60 \%$ of private sector employment, ${ }^{117}$ the absence of specialist HR support is likely to significantly undermine HR professionals as a form of intermediary in many businesses.

Thus, in addition to lacking a central government institution that can facilitate inter-organisational benchmarking, intermediaries are unlikely to contribute meaningfully to organisational scrutiny. Given the concurrent absence of internal and external scrutiny and lack of inter-organisational benchmarking, there are serious questions regarding whether employers are sufficiently accountable for their retirement practices to satisfy an experimentalist architecture.

\footnotetext{
${ }^{114}$ See further L Dickens and M Hall 'Fairness - up to a point. Assessing the impact of New Labour's employment legislation' (2006) 16 Human Resource Management Journal 338, pp 350-1.

${ }^{115}$ BIS Trade Union Membership 2013 (Statistical Bulletin 2014) p 5.

116 See CIPD Managing Age: New Edition 2011 (2011); CIPD Retirement Practices - Making the Right Choice! An Employer's Guide (2010).

117 BIS Business Population Estimates for the UK and Regions 2015 (2015), available at https://www.gov.uk/government/uploads/system/uploads/attachment_data/file/467443/bpe_2015_statis tical_release.pdf.
} 
(iv)REVIEW AND REVISION OF GOALS

Experimentalism needs to be a continuous and ongoing process, with regular reporting; revision of goals, criteria and measures to achieve them; and bench-marking and review, at both the central and local levels. ${ }^{118}$ While goals and criteria need to be continuously revised, ${ }^{119}$ there is no sign of review or revision by the UK government in relation to EJRAs. The EJRA case study organisations anticipated that retirement ages will eventually be removed, and previous governments have signalled their 'longterm aim [of consigning] fixed retirement ages to the past'.${ }^{120}$ However, there appears to be limited in-built review or revision of the law in this area, meaning the 2011 Regulations are not operating within an iterative and experimentalist process of review and revision.

\section{STRENGTHENING EXPERIMENTALISM IN UK}

\section{RETIREMENT RULES}

In sum, then, despite the fact that experimentalism could be a useful architecture in this context and retirement rules could be helpfully developed in this way, the rules relating to retirement in the UK have not been modelled in this fashion. There are no clear goals and measures in relation to retirement; organisational discretion is significantly constrained in practice (if not in theory); there is limited peer review and scrutiny, or accountability through other mechanisms; and there is no evidence of review or revision of retirement rules. As illustrated by the case study, in practice, the 2011 Regulations

\footnotetext{
118 Garrett and Liebman, above n 79, pp 291-2.

${ }^{119}$ Sabel and Simon, above n 7, p 80.

${ }^{120}$ HM Government, above n 67, p 20.
} 
have become fixed rules, which are allowing experimentation in only the most courageous organisations. Given the potential advantages of an experimentalist approach in addressing structural discrimination, it is necessary to consider how retirement rules in the UK could be more effectively modelled as a form of experimentalism.

\section{(a) Goals and measures}

While there are few goals and measures obviously discernible in the 2011 Regulations and other age equality regulations, this is an area that needs additional attention to support an experimentalist approach. While regulatory aims can be identified, they tend to be ill-defined and potentially inconsistent in practice. ${ }^{121}$ However, it is possible to define goals and measures that would appropriately structure organisational discretion in this area, drawing on the legislative framework. Blackham has identified six key objectives or values underlying UK laws relating to ageing and employment, drawing on qualitative and quantitative analysis of legal and policy documents:

1. sustainability of the economy, pension system and workforce;

2. adequacy of income for the elderly;

3. equality;

4. social inclusion;

5. intergenerational solidarity; and

6. organisational efficiency. ${ }^{122}$

\footnotetext{
${ }^{121}$ See Blackham, 'Addressing the ageing workforce: a critical examination of legal policy objectives and values', above n 69 .

${ }^{122}$ Ibid.
} 
These values are all geared towards an individualistic focus, with promoting individual choice a key priority. ${ }^{123}$ Therefore, if seeking to develop goals to orient action around retirement, the key objectives of government policy are to: extend working lives (which is seen as promoting all six values), and promote individual choice.

Identifying goals or benchmarks to measure employers' success in achieving these goals is more problematic. Indeed, unlike in other areas of law, there are no clear and uncontroversial indicators of success for equality legislation. ${ }^{124}$ If relying on quantitative measures of success, this is likely to focus on proportional representation in the workforce, such as workforce participation rates for older workers. ${ }^{125}$ However, quantitative measures (like quotas) are highly controversial in this area. ${ }^{126}$ Further, relying on these measures entails normative judgements about the optimal level of representation for different age groups, and how to most appropriately group people by age. These are difficult questions, on which government has not provided any political or normative guidance. At the same time, numerical indicators may be useful in prompting employers to gather information, review their own workforce composition, and initiate appropriate responses. ${ }^{127}$ Thus, numerical measures are more useful for the process they may initiate, rather than the results they generate. ${ }^{128}$

\footnotetext{
${ }^{123}$ These objectives also drove the abolition of the DRA and introduction of the EJRA. See, for example, BIS, Phasing out the Default Retirement Age: Government Response to Consultation. Impact Assessment, above n 87; BIS, Phasing out the Default Retirement Age: Consultation Document, above $\mathrm{n}$ 87; BIS, Phasing out the Default Retirement Age: Government Response to Consultation, above n 68.

${ }^{124}$ Bagenstos, above n 41, p 37.

${ }^{125}$ Ibid, pp 38-9.

${ }^{126}$ Ibid.

${ }^{127}$ Ibid, pp 45-6.

${ }^{128}$ Ibid.
} 
With this in mind, standards that could be used to assess progress towards these goals include:

- workforce participation rates for older workers;

- average age of retirement; and

- older workers' subjective experiences of individual choice and discrimination.

If taking these criteria and goals into account, it is necessary to acknowledge that retirement ages are largely irrelevant to extending working lives: few workers remain in employment after the state pension age - in 2014 , about $10.3 \%$ of the population $^{129}$ - meaning comparatively few will be affected by the retention or removal of retirement ages. However, maintaining or removing retirement ages may have important symbolic implications, and might serve to, respectively, reinforce or challenge age norms around working and retirement. Further, $10.3 \%$ of the population aged 65 or above equates to over a million workers. ${ }^{130}$ Thus, while reviewing retirement ages might be one way to achieve the posited goals in this area, it is far from the most important priority. Indeed, removing retirement ages may well serve to undermine these goals. The Australian experience shows that removing retirement ages in universities can lead to a reliance on financial incentives to encourage retirement. ${ }^{131}$ This is directly counter to the goals underlying the legislation.

In the alternative, then, the PSED could be reframed as a criterion for assessing organisational progress. Rather than just having 'due regard' to these areas, employers (including universities) could be actually tasked with:

\footnotetext{
${ }^{129}$ OECD.Stat LFS - Sex and Age Indicators (2015).

${ }^{130}$ ONS Labour Market Statistics, June 2014 (2014).

${ }^{131}$ Blackham, 'Managing without default retirement in universities', above n 14.
} 
- eliminating discrimination, harassment, victimisation and any other conduct that is prohibited by or under the EqA;

- advancing equality of opportunity between persons who share a relevant protected characteristic and persons who do not share it; and

- fostering good relations between persons who share a relevant protected characteristic and persons who do not share it.

Employers could be responsible for creating their own criteria to assess their performance against these objectives, ${ }^{132}$ and adopting robust criteria could be used as one indication of good internal processes in this area. ${ }^{133}$ This would encourage a more organisation-specific and iterative approach to achieving equality. Again, retirement ages would form only a small part of this framework of criteria and assessment. This focus on measurable goals is a key contribution of experimentalism.

\section{(b) Peer review and scrutiny}

To facilitate more effective accountability and scrutiny within this framework, three key measures could be introduced. First, employers (both public and private) could be required to report on their progress against the criteria, irrespective as to whether those criteria are set individually by employers themselves, or determined by central and local units in collaboration. Second, the EHRC could be given responsibility and resources to monitor this reporting, and to centrally pool and analyse this information. Third, this information could be shared among employers at facilitated networking and information sharing forums. While these measures reflect the importance of data

\footnotetext{
${ }^{132}$ Sturm, above n 3, p 559.

133 Ibid.
} 
collection and analysis, which is also fundamental to reflexive law and the PSED, ${ }^{134}$ they go beyond a focus on collecting and analysing data to also consider on how it is distributed, pooled and monitored. Thus, this is an area in which experimentalism adds significant value to existing theory.

In the higher education sector specifically, greater use could also be made of the Equality Challenge Unit (ECU) and equality practitioner networks in higher education to promote age equality. ${ }^{135}$ While the ECU already promotes the sharing of good practice in relation to gender and race equality, this could usefully be extended to discussion and information pooling in relation to age equality. The ECU, Athena SWAN scheme and ECU practitioner networks provide practicable examples of how age equality might be progressed within an experimentalist framework. Adding age equality to the ECU's remit is likely to be achievable and practicable, given the institutional structures and legitimacy have already been established in relation to gender equality. While this offers an easy solution for building experimentalism in the higher education sector, it will take far more investment to adopt a similar model in other industries.

\section{(c) Revising rules}

Finally, experimentalism should be an iterative cycle, where goals and criteria are continuously revised on the basis of reporting by organisations. Drawing on a stronger peer review structure for scrutiny, it would also be necessary to put in place mechanisms to facilitate the on-going review of the goals and criteria put in place. This

\footnotetext{
${ }^{134}$ Manfredi, Vickers and Clayton-Hathway, above n 74, pp 393-4.

135 Equality Challenge Unit Your Equality Networks (2016), available at http://www.ecu.ac.uk/getinvolved/equality-networks/.
} 
could take the form of a committee or working group with representatives from employers, government and the EHRC, who could review the operation of the reporting and review cycle, and recommend changes.

\section{CONCLUSION}

The UK has effected substantial changes to its laws relating to retirement ages. Rather than being a form of command and control regulation, the legislative changes appear to be trying to provide a degree of discretion or freedom to employers in the adoption of EJRAs. This recognises the difficulties of imposing rules relating to retirement on diverse organisations which have developed varied human resource practices to reflect their individual needs. In the complex and evolving area of demographic ageing, an experimentalist approach to regulation offers significant advantages over traditional command and control regulation, and may be a more effective way of securing organisational change and the attainment of legislative objectives.

That said, there are significant challenges in trying to model retirement rules as a form of experimentalism, as illustrated by empirical data from the UK university sector. An experimentalist critique of existing retirement rules reveals that it is difficult to discern clear goals or criteria in relation to retirement ages; if goals or criteria exist, they only apply to the minority of employers who have adopted EJRAs, rather than employers as a whole; there is limited discretion afforded to employers in practice, and limited scope for experimentation, as the threat of civil penalties deters creativity in organisational practices; there is limited peer or central scrutiny of organisational practices, minimal information flows and an underdeveloped structured for organisational benchmarking; and there is no process to review or refine goals and criteria. Thus, it is clear that UK retirement rules are not an effective form of 
experimentalism in theory or practice, despite the framing of the legislation to avoid a one-size-fits-all approach.

Given the normative potential of experimentalism to reframe age equality law, this article has presented a range of reforms to strengthen experimentalism in relation to retirement rules. These reforms particularly focus on setting clear goals and criteria, which can already be distilled from legal and policy documents relating to ageing and employment; imposing responsibilities on employers to facilitate information flows and encourage and facilitate organisational peer review; and creating an iterative cycle where goals and criteria can be continually reviewed and revised. These reforms are in keeping with trends towards organisational reporting on equality issues and offer a context-specific yet effective means of improving outcomes for older workers.

While this article has focused on retirement rules, the structures that are proposed are relevant to equality law more broadly. As population ageing continues to be a challenge for employers and governments alike, an experimentalist architecture offers an innovative and critical lens for the reconceptualisation of equality law in the UK. Experimentalism offers a means of building on existing scholarship on reflexive law, to focus on goals and measures, and peer review and scrutiny, as worthy complements to existing reflexive structures. It therefore offers insights for how the UK's focus on reflexive law could be reconceived or strengthened to achieve meaningful change in practice. 